Halaman : $147-152$

\title{
ANALISIS MORAL KNOWING SISWA TENTANG NARKOTIKA DALAM IMPLEMENTASI PENDIDIKAN NILAI KARAKTER
}

\author{
Ika Chastanti*1, Indra Kumalasari $\mathbf{M}^{2}$ \\ ${ }^{1}$ Program Studi Pendidikan Biologi, STKIP Labuhan Batu, Yayasan Universitas Labuhan Batu, Jalan SM. \\ Raja 126 A KM. 3,5, Aek Tapa, Rantauprapat. \\ ${ }^{2}$ Program Studi IImu Hukum, STIH Labuhan Batu, , Yayasan Universitas Labuhan Batu, Jalan SM. Raja \\ 126 A KM. 3,5, Aek Tapa, Rantauprapat. \\ *email: Chastanti.ika@gmail.com
}

\begin{abstract}
Abstrak
Penyalahgunaan narkotika saat ini telah banyak ditemui di kalangan siswa SMP. Narkotika memberikan dampak buruk bagi tubuh dan kehidupan sosial. Pendidikan karakter merupakan solusi untuk mengajarkan pentingnya pengetahuan moral tentang bahaya narkotika. Pendidikan karakter yang baik harus melibatkan pengetahuan yang baik (moral knowing), perasaan yang baik atau loving good (moral feeling) dan perilaku yang baik (moral action) sehingga terbentuk perwujudan kesatuan perilaku dan sikap hidup peserta didik. Tujuan penelitian ini untuk mengetahui moral knowing siswa tentang narkotika. Penelitian ini merupakan penelitan kualitatif yang dilakukan di SMP Negeri 1 Kualuh Hulu. Hasil penelitian ini menunjukkan bahwa ratarata persentase aspek moral knowing siswa pada moral awareness, knowing moral values, perspective taking, moral reasoning, decision making dan self knowledge masih tergolong rendah (38,00\%) menjawab tidak pernah. Hal ini disebabkan karena kurangnya kemampuan guru untuk implementasi pendidikan nilai karakter dan kurangnya peranan pemerintah kabupaten untuk melakukan sosialisasi atau penyuluhan tentang narkotika.
\end{abstract}

Kata kunci : Moral Knowing, Narkotika, Pendidikan Karakter

\begin{abstract}
Absract
Narcotics abuse is now widely found among junior high school. Narcotics can cause adverse effects on the body and social life. Character education is a solution to teach the importance of moral knowledge about the dangers of narcotics. Character education must involve good knowledge (moral knowing), a good feeling or a loving feeling (moral feeling) and good behavior (moral action) so as to form the realization of the unity of behavior and students attitude. The purpose of this study was to determine moral knowing students about narcotics. This research is a qualitative research conducted at SMP Negeri 1 Kualuh Hulu. The results revealed that the average of percentage of students in moral knowing aspects on moral awareness, moral values knowing, perspective taking, moral reasoning, decision making and self knowledge are still relatively low $(38.00 \%)$, answering never. This is due to the lack of teachers' ability to implement character value education and the lack of role of the district government to conduct socialization or counseling about narcotics.
\end{abstract}

Keywords : Character Education, Moral Knowing, Narcotics

\section{PENDAHULUAN}

Kasus penyalahgunaan Narkotika dan obatobatan terlarang di Indonesia semakin meningkat dari tahun ke tahun juga terus mengalami kenaikan dimana pada tahun 2008 ada sebanyak 3.3 juta (3.362.527) dengan pravalensi 1,99\% menjadi pada tahun 2011 menjadi 4 juta (4.071.016) dengan pravalensi $2,32 \%$ dan diprediksikan angka tersebut akan terus mengalami kenaikan pada tahun 2015 menjadi 5,1 juta (5.126.913) dengan prevalensi 2,8\%. (Berdasarkan latar belakang pendidikan, terbanyak pengguna berlatar belakang SMA yaitu
19.730 jiwa, diikuti SMP yaitu 9.768 jiwa. Latar belakang yang paling banyak dari korban penyalahgunaan narkoba adalah tingkat SMA dan remaja (Kemenkes RI, 2014).

Hasil survei BNN pada Tahun 2011, ganja merupakan jenis narkoba yang paling banyak disalahgunakan oleh kalangan siswa. Dampak penyalahgunaan narkoba salah satunya adalah menurunnya prestasi akademik di sekolah. Indikasi ini didukung oleh fakta berikut: hanya $24 \%$ dari penyalahguna yang nilainya diatas rata-rata kelas, bandingkan yang bukan penyalahguna $37 \%$; ada 
Halaman : $147-152$

$11 \%$ penyalahguna yang nilainya dibawah rata-rata kelas, bandingkan yang bukan penyalahguna hanya 5\%; fakta terakhir ada 1 dari 4 penyalahguna yang pernah tidak naik kelas (24\%), bandingkan dengan bukan penyalahguna hanya $10 \%$.

Keadaan ini menandakan bahwa pembelajaran yang didapatkan siswa di sekolah ternyata tidak berdampak pada perilaku siswa. Hal ini terjadi karena proses pembelajaran hanya mengajarkan pendidikan moral sebatas teks dan disebabkan oleh beberapa faktor diantaranya yaitu lingkungan, proses pembelajaran dan perangkat pembelajaran yang digunakan. Sebagian sekolah hanya fokus pada nilai akademik khususnya pada standar nilai ujian nasional, sedangkan aspek non akademik sebagai unsur utama pendidikan karakter diabaikan (Zubaedi, 2011).

Sekolah adalah miniatur masyarakat karena di dalamnya ada struktur, status, fungsi, peran, norma, dan nilai. Sekolah menjadi sarana bagi setiap anak didik untuk belajar memainkan peran dan menjalankan fungsi, setiap anak didik juga diajarkan mengenai tanggung jawab sosial (Muslich, 2010)

Sekolah memiliki tanggung jawab moral untuk mendidik siswa menjadi pintar dan memiliki karakter. Tugas sekolah tidak hanya mengajar, tetapi juga mendidik sehingga siswa tidak hanya memiliki kemampuan kognitif tetapi juga memiliki karakter yang baik. Pendidikan karakter bukan hanya sekedar mengajarkan mana yang benar dan mana yang salah, akan tetapi lebih dari itu pendidikan karakter adalah usaha menanamkan kebiasaan-kebiasaan yang baik (habituation) sehingga peserta didik mampu bersikap dan bertindak berdasarkan nilai-nilai yang telah menjadi kepribadiannya, dengan kata lain, pendidikan karakter yang baik harus melibatkan pengetahuan yang baik (moral knowing), perasaan yang baik atau loving good (moral feeling) dan perilaku yang baik (moral action) sehingga terbentuk perwujudan kesatuan perilaku dan sikap hidup peserta didik (Anonim, 2011).

Pelaksanaan pendidikan karakter di sekolah harus memiliki kegiatan yang terprogram untuk membawa pendidikan nilai yan terkandung di dalamnya. Sekolah hendaknya menciptakan situasi yang memungkinkan bagi siswa untuk menyaksikan, mengetahui dengan pengertian yang benar, serta mengalami sendiri bagaimana nilainilai itu dihayati dan direalisasikan dalam kehidupan sehari-hari. Selain itu, faktor-faktor yang berpengaruh dalam pembinaan karakter adalah (1) guru sebagai sosok panutan harus dapat memberikan contoh dalam bertindak, bersikap, dan bernalar dengan baik; (2) Selebriti yang menjadi idola anak-anak remaja harus dapat memberikan contoh yang baik; (3) orang tua dan teman sejawat juga harus bisa memberikan cermin yang dapat ditiru, siap menjadi tempat curhat, memperhatikan aspirasi, sikap yang menyejukkan, sportif, dan sebagainya; (4) Media massa dan elektronik dengan menampilkan berita dan acara yang memberikan efek positif (Muslich, 2010).

Proses pembentukan karakter adalah bagaimana anak-anak didik diberi pengetahuan dan pemahaman akan nilai-nilai kebaikan yang universal (moral knowing) sehingga pada akhirnya membentuk beliefs. Anak-anak tersebut tidak hanya sampai memiliki pemahaman saja namun sistem pendidikan yang ada juga harus berperan aktif mendukung dan mengondisikan nilai-nilai kebaikan tersebut sehingga semua anak mencintai nilai-nilai tersebut sebagai sebuah kebaik-an untuk dianut (moral feeling). Setelah membentuk pemahaman dan sikap, maka dengan penuh kesadaran anak-anak akan bertindak dengan nilainilai kebaikan (moral behavior) yang dianut sebagai ekspresi martabat dan harga diri (Fransisca dan Ajisuksmo, 2015).

Moral Knowing merupakan hal penting untuk diajarkan. Moral Knowing ini terdiri dari enam hal, yaitu: (1) moral awareness (kesadaran moral); (2) knowing moral values (mengetahui nilai-nilai moral); (3) perspective taking; (4) moral reasoning; (5) decision making; dan (6) self knowledge. Yang perlu disadari adalah mendidik kebiasaan baik saja tidak cukup. Anak yang terbiasa berbuat baik belum tentu menghargai pentingnya nilai-nilai moral (valuing). Oleh karena itu, setelah anak memiliki pengetahuan moral (moral knowing), maka anak dapat menumbuhkan rasa atau keinginan untuk berbuat baik (desiring the good). (Muslich, 2010).

Berdasarkan uraian diatas, maka penelitian ini dilakukan untuk mengetahui moral knowing siswa tentang narkoba dalam ranah implementasi pendidikan nilai karakter. Hal ini perlu dilakukan agar dapat mengetahui kemampuan pemahaman siswa tentang bahaya narkoba.

\section{METODOLOGI}

Penelitian ini dilaksanakan mulai bulan Januari 2018 - Juni 2018 di SMP Negeri 1 Kualuh Hulu. Penelitian ini termasuk penelitian kualitatif yang mana model pendekatan dilakukan dengan kuantitatif pemberian angket dengan 
Halaman : $147-152$

menggunakan skala Likert dan metode Kualitatif yaitu In-depth Interview. Teknik sampling yang digunakan adalah Purposive Sampling yakni pengambilan sampel yang secara sengaja diambil yang didasarkan pada ciri-ciri, sifat, karakteristik tertentu yang merupakan ciri-ciri pokok populasi.

\section{HASIL}

Analisis Moral Knowing Siswa Tentang Narkotika Moral Knowing ini terdiri dari enam hal, yaitu: (1) moral awareness (kesadaran moral); (2) knowing moral values (mengetahui nilai-nilai moral); (3) perspective taking; (4) moral reasoning; (5) decision making; dan (6) self knowledge. Untuk perspective taking diberikan dalam bentuk esai untuk mengetahui sudut pandang siswa, cara berpikir, bereaksi, dan merasakan masalah tentang narkotika Dari hasil pengisian angket yang dilakukan oleh sebanyak 100 koresponden dapat dilihat di bawah ini (Tabel 1).

Tabel 1. Persentase Moral Knowing Siswa tentang Narkoba

\begin{tabular}{|c|c|c|c|c|c|}
\hline \multirow[t]{2}{*}{ No } & \multirow[t]{2}{*}{ Indikator } & \multicolumn{4}{|c|}{ Kategori Moral Knowing Siswa tentang narkoba } \\
\hline & & Selalu & Sering & Kadang-kadang & Tidak Pernah \\
\hline 1. & Moral Awareness & $10,00 \%$ & $12,50 \%$ & $62,50 \%$ & $15,00 \%$ \\
\hline 2. & Knowing Moral Values & $25,00 \%$ & $15,00 \%$ & $46,25 \%$ & $13,75 \%$ \\
\hline 3. & Moral Reasoning & $10,00 \%$ & $8,75 \%$ & $12,50 \%$ & $68,75 \%$ \\
\hline 4. & Decision Making & $2,75 \%$ & $3,75 \%$ & $3,75 \%$ & $90,00 \%$ \\
\hline 5. & Self Knowledge & $22,50 \%$ & $15,00 \%$ & $60,00 \%$ & $2,50 \%$ \\
\hline & Rata-rata & $14,05 \%$ & $11,00 \%$ & $37,00 \%$ & $38,00 \%$ \\
\hline
\end{tabular}

Moral awareness siswa menjawab kadang-kadang (62,50\%). Pada aspek ini kesadaran moral siswa masih rendah karena sebagian besar perilaku siswa masih dipengaruhi oleh temannya tanpa mempertimbangkan perilaku itu baik atau tidak. Siswa seharusnya bisa menyadari apakah tindakanya berdampak positif atau negatif. Menurut Ann. et al (2011) Moral awareness adalah langkah pertama untuk bersikap dengan baik. Setiap orang bertanggungjawab untuk menjaga perilaku ketika mengevaluasi keputusan yang harus dibuat. Setidaknya orang akan memberikan perhatian, mereka menyimpulkan tindakan yang diambilnya adalah hal yang benar untuk dilakukan karena tindakan ini tidak memberikan dampak buruk bagi diri sendiri dan orang lain.

Knowing Moral Values siswa menjawab kadang-kadang (46,25\%). Pada aspek ini siswa belum mampu mengevaluasi mana yang benar dan salah. Nilai moral seharusnya mampu membentuk karakter dan kepribadian siswa. Kejadian yang dialami sekarang adalah siswa tidak mengikuti kehidupan moralnya dengan baik. Berdasarkan jawaban siswa bahwa siswa tidak bertanggung jawab jika melakukan kesalahan yang mana ini menunjukkan bahwa siswa belum bisa mengevaluasi tindakan yang telah dilakukannya. Nilai moral dalam pendidikan karakter adalah integritas, kejujuran, kepercayaan, bersikap hormat kepada orang lain. Nilai moral ini mampu membantu untuk membedakan mana yang benar dan salah, baik dan buruk bagi seseorang dalam kehidupan sosialnya (Muslich, 2010).

Moral Reasoning siswa menjawab tidak pernah (68,75\%). Berdasarkan jawaban siswa dapat dilihat bahwa siswa tidak pernah mencari tahu dampak narkoba bagi tubuh dan jika siswa mencoba narkoba maka siswa tidak akan memberitahukannya kepada orang tua. Moral Reasoning dikenal juga dengan perkembangan moral. Moral Reasoning merupakan proses bagi seseorang yang mencoba untuk mengevaluasi perbedaan antara benar dan salah dengan menggunakan logika. Proses ini sangat penting dan sering terjadi dalam keseharian ketika seseorang mencoba untuk melakukan hal benar. Setiap hari seseorang dihadapkan dengan dilema apakah berbohong atau tidak dalam situasi tertentu. Seseorang akan membuat keputusan dengan alasan moralitas dari tindakan yang dilakukannya (Sachdeva, dan Medin, 2011).

Decision Making siswa dengan persentase $90,00 \%$ menjawab tidak pernah. Pada pengambilan keputusan menunjukkan bahwa siswa berhati-hati ketika ada orang asing yang menawarkan barang yang tidak mereka ketahui jenisnya. Siswa tidak akan menerima imbalan uang dari orang asing untuk mencoba barang tersebut. Ketika membuat keputusan moral, hal yang harus diingat adalah kita memiliki hubungan sosial dengan orang lain 
Halaman : $147-152$

dan tindakan kita akan memengaruhi mereka dalam cara yang berbeda. Dalam pengambilan keputusan harus dipikirkan konsekuensi positif dan negatif yang menjadi bagian dari keputusan yang diambil, walaupun terkadang membuat keputusan moral akan menghasilkan konsekuensi negatif dan jika situasi ini terjadi maka pastikan keputusan yang diambil adalah sisi yang benar (Muslich, 2010).

Self Knowledge siswa menjawab kadangkadang (60,00\%). Hasil menunjukkan bahwa kemampuan moral siswa dalam mengenali diri sendiri masih belum baik. Pengetahuan tentang diri masing-masing sangat diperlukan dalam pendidikan karakter. Menjadi orang yang bermoral memerlukan keahlian untuk mengulas perilaku diri sendiri dan mengevaluasi perilakunya secara kritis. Sumber Self Knowledge bisa dipahami dengan teori Self-Perception yang mana seseorang akan belajar tentang orang lain dengan menguji tingkah laku. Jika situasi secara menyeluruh menjelaskan tentang tingkah laku kita, maka akan dibuat gambaran kesimpulan, tetapi jika situasi tidak menjelaskan secara keseluruhan, maka seseorang akan menggambar kesimpulan tentang apa yang disukai (Bem, 1972).

Perspesctive Taking dilakukan dengan memberikan pertanyaan essai kepada siswa untuk mengetahui sudut pandang siswa, cara berpikir, bereaksi, dan merasakan masalah tentang narkotika. Pada Perspesctive Taking, siswa masih banyak yang belum mampu menggambarkan narkotika dari sudut pandang mereka. Siswa belum mampu berpikir tentang bahaya narkotika bagi tubuh, siswa belum mampu bereaksi dan merasakana masalah dengan benar jika salah satu temannya atau warga di lingkungannya mengkonsumsi narkotika. Perkembangan kemampuan perspective taking memiliki rentang perkembangan mulai dari perspective taking yang belum matang dan perspective taking yang matang. Kemampuan perspective taking yang matang merupakan kemampuan sosial yang perlu dimiliki oleh remaja sehingga remaja mampu menciptakan lingkungan sosial dan relasi yang positif antara diri dengan orang lain. Manfaat lainnya adalah meningkatkan kemampuan resolusi konflik (Cooney at al. 2014) dan mengurangi agresi interpersonal (Davis, 1983). Menurut Castro (2016), kemampuan perspective taking matang ditandai dengan adanya "lompatan"/ "melampaui" diri. Individu mampu memahami pikiran, keyakinan, dan perilaku orang lain di suatu situasi sehingga membantu diri dan orang lain menciptakan emosi positif. Lain halnya dengan kemampuan perspective taking yang belum matang. la kurang mampu memahami sudut pandang yang berbeda antara dirinya dengan orang lain.

\section{PEMBAHASAN}

Hasil angket menunjukan bahwa Moral Knowing siswa masih tergolong rendah $(38,00 \%)$ tentang narkotika, yang mana seharusnya guru mampu menanamkan pendidikan nilai kepada siswa tentang bahaya narkotika, dampak negatif bagi tubuh dan kehidupan sosial, serta jenis-jenis narkotika yang ada. Selain guru, orang tua juga tetap harus membimbing anak sampai pada tahap implementasi dalam kehidupan sehari-hari. Berdasarkan hasil wawancara dengan siswa mengatakan bahwa guru jarang menyampaikan dampak buruk narkotika dalam proses pembelajaran, bahkan guru tidak pernah menyebutkan jenis-jenis narkotika sehingga siswa tidak mengetahuinya. Pemerintah Kabupaten juga tidak pernah mengadakan sosialisasi ataupun penyuluhan tentang narkotika. $\mathrm{Hal}$ ini menunjukkan bahwa masih kurangnya peranan dunia pendidikan dan pemerintah kabupaten untuk aspek moral knowing siswa tentang narkotika.

Persoalan narkoba merupakan persoalan yang harus ditangani secara sungguh-sungguh oleh seluruh komponen masyarakat. Bukan saja penanganan bagi penggunanya, melainkan juga perkembangan bisnis narkoba yang ada di Indonesia sudah mulai menggelisahkan (Sholihah, 2015). Pengetahuan merupakan faktor penyalahgunaan narkotika, dimana pengetahuan akan mempengaruhi tindakan apa yang akan dia ambil. Dalam penelitian yang dilakukan Wishesa didapatkan hasil bahwa terdapat hubungan yang signifikan antara tingkat pengetahuan dengan penyalahgunaan narkoba. Selain itu sosialisasi tentang penyalahgunaan narkoba yang masih kurang kurang selama ini juga disebabkan adanya keterbatasan tenaga penyuluh dan sumber-sumber pendukung lainnya berupa sarana dan prasarana seperti ketersediaan buku-buku tentang bahaya narkoba maupun video-video tentang bahaya penyalahgunaan narkoba serta media elektronik lainnya, sehingga berdampak dari kurang optimalnya pelaksanaan program pencegahan penyalahgunaan narkoba (Udana M, 2013).

Narkotika sampai saat ini telah banyak merusak generasi bangsa terutama siswa baik di kalangan SMP maupun SMA. Pada siswa SMP 
Halaman : $147-152$

(BNN, 2016), seharusnya guru mampu memberikan pengarahan dan secara intens mengawasi siswa agar tidak terlibat dalam penyalahgunaan narkotika. Salah satu faktor yang berpengaruh terhadap penyalahgunaan narkotika adalah pengetahuan, dimana dalam suatu kondisi jika seseorang itu tahu bahwa hal yang akan dilakukannya akan berakibat buruk terhadap dirinya maka orang tersebut kemungkinan tidak akan melakukan hal tersebut (Menthan, 2013). Peningkatan pengetahuan dapat dilakukan dengan cara penyuluhan. Hal ini sejalan dengan penelitian yang menyatakan bahwa ada peningkatan pengetahuan yang signifikan setelah pemberian penyuluhan (Badri M, 2013).

Penyalahgunaan narkotika biasa didasari atas beberapa hal yang menyebabkan seseorang menjadi penyalahguna narkotika. Pada dasarnya dapat dikelompokkan menjadi dua bagian besar. Pertama, sebab-sebab yang berasal dari faktor individu seperti pengetahuan, sikap, kepribadian, jenis kelamin, usia, dorongan kenikmatan, perasaan ingin tahu, dan untuk memecahkan persoalan yang sedang dihadapi. Kelompok kedua berasal dari lingkungannya seperti pekerjaan, ketidakharmonisan keluarga, kelas sosial ekonomi, dan tekanan kelompok (Badri M, 2013).

Pendidikan sebagai proses alih nilai mempunyai 3 sasaran utama yaitu: (1) pendidikan bertujuan untuk membentuk manusia yang mempunyai keseimbangan antara kemampuan kognitif dan psikomotorik di satu pihak dan kemampuan efektif di pihak lain; (2) dalam sistem nilai "dialihkan" juga termasuk nilai-nilai keimanan dan ketakwaan; (3) transformasi tata nilai yang mendukung proses industrialisasi dan penerapan teknologi (Muslich, 2010) Guru sebagai ujung tombak pendidikan, memiliki peran yang sangat sentral dalam mewujudkan siswa yang berkarakter. Guru selain dituntut untuk menyampaikan materi, guru juga harus mampu menjadi sosok yang ditiru oleh siswa. Untuk bisa ditiru oleh siswa seharusnya guru mampu menjaga etika ketika berada di lingkungan sekolah agar implementasi pendidikan nilai dapat tercapai.

Moral knowing siswa perlu dibentuk agar siswa memiliki bekal pengetahuan sehingga karakter siswa yang telah terbentuk akan menjadi kebiasaan yang baik. Manusia memiliki kemauan yang bebas dan setiap orang harus mampu membuat pilihan moral yaitu memutuskan antara benar dan salah. Manusia secara alami memiliki kecenderugan untuk melihat dan mengaspirasi halhal yang baik. Sumber-sumber moralitas secara umum ada 5 yaitu: (1) keluarga merupakan sumber pertama dan penting dalam pembentukan karakter, orang tua mengajarkan anak-anaknya untuk mampu membedakan antara baik dan buruk, benar dan salah. Anak belajar menghormati orang lain dan membawa karakter baik tersebut sepanjang hidupnya; (2) Teman yang membantu anak untuk menjadi lebih percaya diri. Teman membuat anak lebih menghormati orang lain dan mampu merasakan perasaan orang lain tetapi terkadang teman juga mampu membawa pengaruh buruk untuk karakter anak; (3) Sekolah membantu membentuk karakter siswa. Sekolah memiliki aturan yang membantu membentuk karakter, sekolah memiliki tujuan untuk mengajarkan moralitas dan konsekuensi dari tindakan siswa; (4) Agama yang selalu mengajarkan kebaikan bagi penganutnya; (5) Negara yaitu pemerintah membuat dasar hukum bagi warga negaranya yang melakukan tindak kriminal. Selain itu, sumber moralitas lainnya adalah (1) Media, yang seharusnya memberikan pesan moral yang mampu membuat keputusan moral ketika dihadapkan pada masalah moral; (2) Emosi seperti sikap simpati yang mampu menolong seseorang yang dalam kesulitan, dan amarah serta kebencian yang memberikan konsekuensi negatif pada tindakan (Muslich, 2010).

\section{KESIMPULAN}

Moral Knowing siswa tentang narkotika masih tergolong rendah. Sebagian siswa tidak mengetahui dampak buruk narkotika bagi tubuh, bahkan siswa tidak mengetahui jenis-jenis narkotika. Kurangnya peranan guru dan pemerintah kabupaten dalam menekankan bahaya narkotika menjadi penyebab pengetahuan moral siswa rendah. Saran untuk perkembangan lanjutan diharapkan akan dilakukan penelitian untuk melakukan program tertentu untuk meningkatkan Moral Knowing siswa tentang narkotika.

\section{UCAPAN TERIMA KASIH}

Ucapan terima kasih peneliti sampaikan kepada ALLAH SWT dan Kemenristek Dikti yang telah mendanai penelitian ini, penulis mengucapkan terima kasih dan penghargaan sebesarnya kepada Orang tua dan SMP Negeri 1 Kualuh Hulu Kabupaten Labuhanbatu Utara yang telah memberikan kesempatan kepada penulis untuk melaksanakan penelitian di sekolah hingga selesai.

\section{DAFTAR PUSTAKA}


Halaman : $147-152$

Anonim. 2011. Pedoman Pelaksanaan Pendidikan Karakter. Jakarta: Badan Penelitian dan Pengembangan Pusat Kurikulum.

Bazerman, May. H, Ann E. 2011. Blind Spots: Why We Fail To Do What's Right and What To Do About It. Princeton NJ: Princeton University.

Badri M. Implementasi Undang-Undang No. 35 Tahun 2009 Tentang Narkotika Dalam Pelaksanaan Wajib Lapor Bagi Pecandu Narkotika. Jurnal Ilmiah Universitas Batanghari Jambi. 13 (3): 7-12.

Bem, O.J. 1972. Self- Perception Theory .Advances In Experimental Social Psychology. Vol. 6. Hal. $1-63$.

BNN dan Puslitkes UI. 2016. Survei Perkembangan Penyalahgunaan dan Peredaran Gelap Narkoba pada Kelompok Pelajar di Indonesia.

Castro, J.R. (2016). Perspective Taking and Threat: Do Threatening Situations Have an Effect on Helping Intentions and Perceived Expectations. Disertasi. Syracuse University.

Davis, M.H. (1983). Measuring Individual Differences in Empathy: Evidence $A$ Multidimensional Approach. Journal of Personality and Social Psychology, 44 (1): 113126

Dugan, J.P., Bohle, C.W., Woelker, L.R., \& Cooney, M.A. (2014). The Role of Social PerspectiveTaking in Developing Students' Leadership Capacities. Journal of Student Affairs Research and Practice, 51 (1): 1-15.

Fransisca, Leonie, Ajisuskmo Clara. 2015. Keterkaitan antara Moral Knowing, Moral Feeling, dan Moral Behaviour pada Empat Kompetensi Dasar Guru. Jurnal Kependidikan. Vol. 45: (2). Hal. 211-221.

Kemenkes RI. 2014. Infodatin Say No To Drugs Say Yes To Live I. Jakarta: Kementerian Kesehatan Republik Indonesia.

Menthan, Fadrian. 2013. Peranan Badan Narkotika Nasional Kota Samarinda dalam Penanggulangan Masalah Narkoba di Kalangan Remaja Kota Samarinda. Ejournal Administrasi Negara, 1 (2): 544-557.

Sachdeva Singh, Medin, D. 2011. Culture and The Quest for Universal Principals in Moral Reasoning. International Journal of Psychology. Vol. 46: (3). Hal. 161-176.

Sholihah, Qomariyatus. 2015. Efektivitas Program P4GN Terhadap Penyalahgunaan NAPZA.
Jurnal Kesehatan Masyarakat. Vol 9 (1). Hal. $153-159$.

Udana M. 2013. Implementasi Program Pencegahan Penyalahgunaan Narkoba Oleh BNN Kota Pontianak pada Siswa SMAN 2 Kota Pontianak. Jurnal S1 Ilmu Administrasi Negara 2 (2): 1-9.

Muslich, Masnur. 2011. Pendidikan Karakter: Menjawab Tantangan Multidimensional. Jakarta: Bumi Aksara.

Zubaedi. 2011. Desain Pendidikan Karakter Konsepsi dan Aplikasinya dalam Lembaga Pendidikan. Jakarta: Prenada Media. 